\title{
Dampak Erupsi Gunung Merapi Terhadap Nilai Lahan dan Bangunan: Pendekatan Hedonic Price
}

\author{
Endah Saptutyningsih \\ Universitas Muhammadiyah Yogyakarta \\ email:end_naufal@yahoo.com
}

\begin{abstract}
This study aims to conduct economic valuation of volcanic eruption impacts in disaster prone areas of Merapi eruption. Economic valuation of flood disaster impacts were calculated using the hedonic price method. The disaster prone areas of Merapi eruption are the area especially located in Sleman Regency, they are Turi, Pakem, Cangkringan, and Ngemplak Districts.

The results of this study indicate that the hedonic price method can be applied in Sleman Regency to obtain estimates marginal damage to property value caused by flooding. The significance of height level of deposits of volcanic material coefficient shows that flood is indeed depressing the agricultural land value. The sample household's average marginal willingness to pay (MWTP) for a unit decrease in height level of deposits of volcanic material in their agricultural land is estimated at a reasonable amount of $\mathrm{Rp}$ 653,800.00. By conducting economic valuation in the Sleman Regency, is expected to be also done in other areas vulnerable to volcanic eruption disasters.
\end{abstract}

Keywords: hedonic price, economic valuation, marginal willingness to pay, agricultural land

\section{Pendahuluan}

Pada 26 Oktober 2010 hingga awal November 2010 telah terjadi bencana erupsi Gunung Merapi yang terletak di perbatasan Provinsi DI Yogyakarta dengan Provinsi Jateng. Berdasarkan data Pusdalops BNPB per tanggal 27 November 2010, bencana erupsi Gunung Merapi ini telah menimbulkan korban jiwa sebanyak 242 orang meninggal di wilayah DI Yogyakarta dan 97 orang meninggal di wilayah Jateng.

Selain menimbulkan korban jiwa dan luka-luka, bencana erupsi Gunung Merapi ini juga telah mengakibatkan kerusakan dan kerugian besar di sejumlah desa dan kecamatan yang tersebar di empat kabupaten, yakni Kabupaten Magelang, Boyolali dan Klaten di Provinsi Jateng, dan Kabupaten Sleman di Provinsi DI Yogyakarta. Di Kabupaten Sleman, erupsi Gunung Merapi mengakibatkan kerusakan bangunan rumah yang diperkirakan sebesar Rp. 477.569.544.000,dengan wilayah yang meliputi kecamatan Cangkringan, Ngemplak dan Turi. Kerusakan terjadi lebih banyak di wilayah Cangkringan dengan jumlah sebesar 3.346 rumah dengan rincian kerusakan dengan kondisi berat sebesar 2.587 rumah, rusak sedang sebesar 140 rumah dan rusak ringan sebesar 619 rumah. Untuk wilayah Ngemplak kerusakan rumah dengan kondisi berat sebanyak 26, rusak sedang sebayak 12 rumah dan rusak ringan 11 rumah sedangkan untuk wilayah turi kerusakan rumah terjadi sebanyak 6 rumah dengan 4 rumah mengalami kerusakan sedang dan 2 rumah lagi mengalami kerusakan ringan. 
Sedangkan harga untuk masing-masing unit kerusakan rumah tinggal sebesar Rp. 154.070.000 dengan total harga kerusakan di wilayah Cangkringan sebesar Rp. 440.131.769.000, untuk wilayah Ngemplak sebesar Rp. 5.623.555.000 dan wilayah Turi sebesar Rp. 462.210.000 (Departemen Pekerjaan Umum, 2011).

Tabel 1. Rekapitulasi Nilai Kerusakan Sektor Pertanian di Kabupaten Sleman

\begin{tabular}{|l|r|r|r|c|}
\hline \multicolumn{1}{|c|}{ Komoditas } & Luas/rumpun/batang & Nilai Kerugian (Rp.) & Persentase kerugian \\
\hline Padi Sawah & 238 & $\mathrm{Ha}$ & 2.795 .131 .440 & $1,07 \%$ \\
\hline Sayur & 845 & $\mathrm{Ha}$ & 38.048 .675 .000 & $14,58 \%$ \\
\hline Salak Pondoh & 4.382 .925 & $\mathrm{Rpn}$ & 218.973 .254 .400 & $83,93 \%$ \\
\hline Tanaman Hias & 209.365 & $\mathrm{Btg}$ & 1.011 .200 .000 & $0,39 \%$ \\
\hline Palawija & 35 & $\mathrm{Ha}$ & 75.800 .000 & $0,03 \%$ \\
\hline \multicolumn{1}{|c|}{ Total } & & & 260.904 .060 .840 & \\
\hline
\end{tabular}

Sumber: Dinas Pertanian, Perikanan dan Kehutanan Kabupaten Sleman (2011)

Dari Tabel 1 menunjukkan bahwa jenis tanaman padi sawah seluas 238 Ha mengalami kerusakan, persentase nilai kerugian sebesar 1,07\% dari seluruh tanaman di Kabupaten Sleman dengan nilai kerugian sebesar Rp. 2.795.131.400,00. Untuk sayur seluas $845 \mathrm{Ha}$, persentase kerugian sebesar 14,58\% dengan nilai kerugian sebesar Rp. 38.048.675.000,00. Tanaman salak pondoh sebanyak 4.382.925 rumpun mendominasi kerugian pertanian 83,93\% dari tanaman di Kabupaten Sleman dengan nilai kerugian sebesar Rp. 218.973.254.400,00. Sedangkan untuk tanaman hias sebanyak 209.365 batang mengalami kerugian 0,39\% dengan nilai kerugian mencapai Rp. 1.011.200.000,00. Tanaman palawija seluas $35 \mathrm{Ha}$ mengalami kerugian sebesar 0,03\% dengan nilai kerugian mencapai Rp. 260.904.060.840,00.

Penelitian mengenai kebencanaan telah banyak dilakukan. Analisis mengenai kebencanaan dapat dikelompokkan menjadi dua yaitu kelompok pertama yang menganalisis dari faktor fisik dan kelompok kedua yang menganalisis dari faktor non fisik. Faktor-faktor non fisik yang ditinjau meliputi ekonomi, sosial, budaya, hukum-hukum dan lain-lain. Analisis mengenai sektor ekonomi pun bisa bervariasi apakah penelitian mengenai manajemen risiko, proyek mitigasi, valuasi dampak bencana, dan masih banyak lagi.

Penelitian ini menganalisis tentang valuasi ekonomi dampak bencana erupsi gunung berapi yang dapat disebabkan beberapa faktor. Metode penghitungan valuasi ekonomi ini disesuaikan dengan kasus kebencanaan sehingga diharapkan teknik valuasi yang dilakukan tepat untuk digunakan. Dengan melakukan valuasi ekonomi di Daerah Istimewa Yogyakarta, diharapkan dapat juga dilakukan di daerah-daerah lain yang rawan bencana khususnya bencana erupsi gunung berapi.

Model hedonic property value akan digunakan untuk memperkirakan manfaat bagi rumah tangga lokal untuk mengurangi risiko erupsi gunung Merapi di kabupaten Sleman Daerah Istimewa 
Yogyakarta (DIY). Manfaat total yang terdiri dari manfaat ekonomi, dan manfaat pemulihan lingkungan dari pengurangan risiko erupsi gunung Merapi dapat diperkirakan dengan menggunakan model hedonic property value model.

Penelitian ini menganalisis tentang valuasi ekonomi dampak erupsi gunung Merapi yang dapat disebabkan beberapa faktor. Metode penghitungan valuasi ekonomi ini disesuaikan dengan kasus bencana erupsi gunung berapi sehingga diharapkan teknik valuasi yang dilakukan tepat untuk digunakan. Dengan melakukan valuasi ekonomi di Kabupaten Sleman Daerah Istimewa Yogyakarta, diharapkan dapat juga dilakukan di daerah-daerah lain yang memiliki risiko bencana gunung berapi.

Model hedonic property value ini akan digunakan untuk memperkirakan manfaat bagi rumah tangga lokal untuk mengurangi risiko akibat erupsi gunung Merapi.

Tabel 2. Penelitian-penelitian yang terdahulu

\begin{tabular}{|l|l|l|}
\hline Nama Peneliti & \multicolumn{1}{|c|}{ Metode } & \multicolumn{1}{c|}{ Hasil Penelitian } \\
\hline $\begin{array}{l}\text { Daniel, Florax, } \\
\text { dan Rietveld }\end{array}$ & Hedonic price & $\begin{array}{l}\text { Dampak total banjir terhadap nilai rumah yang dipengaruhi oleh } \\
\text { gelombang tinggi menurun antara 7-13\%. Penurunan ini tidak } \\
\text { muncul setelah beberapa tahun, mungkin dikarenakan } \\
\text { peningkatan perhatian terhadap resiko banjir dalam media. }\end{array}$ \\
\hline $\begin{array}{l}\text { Murty et.al } \\
(2003)\end{array}$ & Hedonic price & $\begin{array}{l}\text { Terdapat hubungan positif antara marginal WTP dan variable } \\
\text { pendapatan dan pendidikan }\end{array}$ \\
\hline Moaz (2005) & Hedonic price & $\begin{array}{l}\text { Tingkat polusi menurunkan nilai rumah. Rata-rata MWTP untuk } \\
\text { setiap penurunan konsentrasi TSP adalah US\$ 60.00 }\end{array}$ \\
\hline Patrick (2006) & Hedonic price & $\begin{array}{l}\text { Besarnya uang yang mau dibayarkan rumah tangga untuk setiap } \\
\text { pengurangan 1 unit konsentrasi PM10 memiliki median sebesar } \\
\text { \$149 sampai \$185 }\end{array}$ \\
\hline
\end{tabular}

\section{Tujuan Penelitian}

Tujuan penelitian ini adalah melakukan valuasi ekonomi dampak yang diakibatkan erupsi gunung Merapi terhadap nilai bangunan dan lahan pertanian di kawasan rawan bencana Merapi.

\section{Metodologi}

\section{Jenis dan Sumber Data}

Jenis data yang digunakan adalah data primer dan data sekunder, data primer adalah data yang diperoleh secara langsung dari sumber data. Alat yang digunakan untuk mendapatkan data tersebut adalah kuesioner. Sedangkan metode yang digunakan untuk memperoleh data primer adalah metode survei dengan teknik wawancara langsung (direct interview) dengan dibantu daftar pertanyaan (kuesioner). Data yang diperlukan berupa kerugian langsung maupun tidak langsung yang dialami masyarakat korban di wilayah rawan bencana erupsi Merapi. 
Jenis data yang kedua adalah data sekunder, data sekunder adalah data yang diperoleh dari instansi dan lembaga-lembaga terkait di wilayah rawan bencana erupsi Merapi di Kabupaten Sleman DI Yogyakarta. Adapun data sekunder yang dibutuhkan diantaranya nilai jual properti (Nilai Jual Obyek Pajak (NJOP)), jarak dari gunung Merapi, tinggi timbunan material vulkanik, dan lain-lain. Data-data tersebut dapat diperoleh dari instansi-instansi terkait antara lain: Kantor Pajak Bumi dan Bangunan, Dinas Pekerjaan Umum, Dinas Pertanian, Perikanan dan Kehutanan Kabupaten Sleman, dan sebagainya.

\section{Metode Pengumpulan Data}

a. Focus Group

Penelitian ini akan menggunakan pendekatan hedonic price yang akan menganalisis berbagai faktor yang berpengaruh terhadap harga properti di daerah paling rawan erupsi gunung Merapi di Kabupaten Sleman. Survei dilakukan untuk mengeksplorasi berbagai karakteristik bangunan, lingkungan fisik maupun sosial masyarakat di daerah tersebut. Mitchell dan Carson (1989) menyarankan penggunaan focus group dan pre-test dalam rangka menyusun struktur pertanyaan WTP terbaik. Tujuan utama focus group adalah menyingkap cara terbaik untuk menanyakan pertanyaan yang sangat teknis terkait harga bangunan dan lahan.

b. Pre-test

Pre-test digunakan untuk memperkirakan waktu yang dibutuhkan untuk survei, mengidentifikasi isu lebih lanjut atau klarifikasi yang diperlukan bagi pertanyaan dalam kuesioner dan membuat format akhir pertanyaan yang akan digunakan. Modifikasi sedikit dibuat pada pertanyaan terkait hedonic price mengikuti perubahan yang didukung oleh focus group.

c. Survei Final

Survei dilakukan di daerah rawan erupsi gunung berapi dengan responden. Selain pertanyaan terkait harga dan karakteristik bangunan, survei juga memasukkan pertanyaan tentang lingkungan fisik dan sosial, serta kepedualian masyarakat terhadap lingkungan.

\section{Teknik Pengambilan Sampel}

Metode studi pustaka digunakan untuk mengumpulkan data sekunder yang terkait dengan penghitungan kerugian akibat bencana erupsi gunung berapi di daerah rawan erupsi gunung berapi. Sedangkan data primer diperoleh dengan diambil sampelnya terlebih dahulu dengan menggunakan 
strategic random sample (Scheaffer et.al., 1996), berarti bahwa semua rumah yang berlokasi di wilayah rawan bencana erupsi gunung Merapi dibagi dalam beberapa blok, dan kemudian sampel diacak untuk setiap blok. Sampel digunakan karena tidak semua unit pada populasi dapat diidentifikasi, biaya dan waktu yang digunakan lebih sedikit dibandingkan menghitung populasi. Ukuran sampel yang digunakan berdasarkan formula Watson et al. (1993) adalah:

$n=\frac{4 Z_{1 / 2 \alpha}^{2} p(1-p)}{(\omega)^{2}}$

di mana:

$\mathrm{n} \quad=$ ukuran sampel

$\mathrm{p} \quad=$ proporsi kesuksesan yang diharapkan dari sampel

$\mathrm{q} \quad=$ proporsi sisa $(1-\mathrm{p})$

$\mathrm{Z}_{1 / 2 \alpha}=$ koefisien konfidensi

$\omega \quad=$ jumlah kesalahan yang dapat ditoleransi dari rerata populasi pada batas kiri (L) dan batas kanan $(\mathrm{R})$, sehingga $\omega=\mathrm{L}+\mathrm{R}$

\section{Definisi Operasional}

1. Valuasi ekonomi adalah pemberian nilai (value) secara ekonomi pada suatu kejadian atau dampak terhadap sumber daya alam dan lingkungan, di mana manusia sebagai subjek dan objek dari kegiatan yang menyebabkan terjadinya dampak tersebut (Titienberg, 1998)

2. Variabel property menjelaskan karakteristik properti (khususnya rumah) meliputi jumlah ruang, jumlah kamar mandi, usia bangunan, ukuran tanah, ukuran bangunan, tipe bangunan (permanen, semi permanent, tidak keduanya)

3. Variabel lahan menjelaskan karakteristik lahan pertanian meliputi status kepemilikan, ukuran lahan, jenis lahan, komoditas yang dihasilkan, hasil yang diperoleh dalam sekali panen.

4. Variable neighborhood mencakup jarak dengan pusat perekonomian, jarak dengan pusat kesehatan, jarak dengan pusat pendidikan (Brookshire, Thayer, Schulze and d'Arge (1982). Untuk obyek berupa lahan, maka variable neighborhood meliputi jarak dengan fasilitas umum, pernah/tidaknya gagal panen, kerugian yang dialami.

5. Variabel lingkungan menunjukkan karakteristik resiko erupsi gunung Merapi meliputi jarak tempat tinggal ke gunung Merapi, tinggi timbunan material vulkanik. 


\section{Alat Analisis}

Nilai kerugian yang diakibatkan oleh bencana erupsi gunung berapi akan dinilai dengan menggunakan metode hedonic price. Metode ini menganggap bahwa nilai sebagian lahan berhubungan dengan aliran manfaat yang diturunkan dari lahan. Output pertanian dan tempat tinggal adalah contoh manfaat seperti ini, tetapi akses ke tempat kerja, ke commercial amenities, dan ke fasilitas lingkungan seperti taman, dan kualitas lingkungan sekitar dimana lahan berlokasi juga merupakan manfaat penting yang ditambahkan kepada orang yang memiliki hak untuk menggunakan sebagian lahan. Pendekatan property value untuk pengukuran estimasi manfaat didasarkan pada asumsi berikut. Dianggap bahwa lokasi yang berbeda memiliki atribut lingkungan yang bervariasi, variasi seperti ini akan mengakibatkan perbedaan dalam nilai property.

Perbedaan nilai residential property dapat muncul akibat dari berbagai sumber seperti jumlah dan kualitas akomodasi yang tersedia, aksesibilitas pusat bisnis, level dan kualitas fasilitas publik, tingkat pajak yang dibayarkan atas properti, dan karakteristik lingkungan sekitar, ketika diukur ketinggian timbunan material gunung Merapi dan akses ke pusat-pusat ekonomi, kesehatan, dan pendidikan. Dalam rangka mengambil efek variabel-variabel ini terhadap nilai suatu properti, mereka semua harus dimasukkan dalam analisis. Oleh karena itu, studi-studi biasanya melibatkan sejumlah variabel property, sejumlah variabel neighbourhood, dan variabel lingkungan. Jika variabel yang relevan tidak dimasukkan dalam analisis, maka efek terhadap nilai properti yang diestimasi dapat bias. Apakah bias naik atau turun akan tergantung pada bagaimana variabel yang dimasukkan atau tidak dimasukkan berhubungan satu sama lain dan berhubungan dengan nilai properti.

Valuasi ekonomi terhadap resiko erupsi gunung Merapi dengan menggunakan metode hedonic price (Vanessa, Raymond, and Piet Rietveld, 2007). Dalam penelitian ini digunakan dua model hedonic price. Model pertama menggunakan variabel terkait dengan harga property/bangunan khususnya rumah sedangkan model kedua menggunakan variable terkait dengan harga lahan.

Property/Land price = f(variabel property, variabel neighborhood, variabel lingkungan)

atau $\quad \mathrm{PP}=\mathrm{f}($ PROP, NHOOD, ENV)

dimana PP adalah harga properti, PROP adalah karakteristik properti, NHOOD adalah karakteristik yang terkait dengan lokasi properti, ENV adalah variable risiko erupsi Merapi yang terkait dengan harga properti.

Menurut beberapa studi empiris (Palmquist, Roka, dan Vukina, 1997), kita mengestimasi bentukbentuk fungsional dan menyeleksi model yang terbaik berdasarkan nilai $\mathrm{R}^{2}$ yang tertinggi. 


\section{Hasil dan Pembahasan}

Berdasarkan hasil survey (lihat Tabel 3), sebelum erupsi Merapi terdapat 48,4\% masyarakat yang memiliki pendapatan diantara Rp 500 ribu sampai Rp 1 juta rupiah per bulan, 29,1\% memiliki pendapatan anatara Rp 250 ribu sampai Rp 500 ribu rupiah per bulan. Sedangkan sisanya memiliki pendapatan lebih dari Rp 500 ribu per bulan.

Tabel 3. Pendapatan Sebelum Erupsi Merapi

\begin{tabular}{|l|r|r|r|}
\hline \multicolumn{1}{|c|}{ Tingkat Pendapatan } & \multicolumn{1}{c|}{ Frekuensi } & Persentase (\%) & \% Kumulatif \\
\hline $250-500 \mathrm{ribu} /$ bulan & 62 & 29.1 & 29.1 \\
\hline $500 \mathrm{ribu}-1$ juta/bulan & 103 & 48.4 & 77.5 \\
\hline 1 juta-2 juta/bulan & 29 & 13.6 & 91.1 \\
\hline$>1$ juta/bulan & 19 & 8.9 & 100.0 \\
\hline
\end{tabular}

Setelah adanya erupsi Merapi sebagian besar masyarakat mengalami penurunan pendapatan (lihat Tabel 4), terutama yang berpendapatan di atas Rp 500 ribu rupiah per bulan. 89,4\% masyarakat memiliki pendapatan di bawah Rp 500 ribu rupiah per bulan.

Tabel 4. Pendapatan Setelah Erupsi Merapi

\begin{tabular}{|l|r|r|r|}
\hline \multicolumn{1}{|c|}{ Tingkat Pendapatan } & \multicolumn{1}{c|}{ Frekuensi } & Persentase (\%) & \% Kumulatif \\
\hline$<250 \mathrm{ribu} / \mathrm{bulan}$ & 23 & 13.5 & 13.5 \\
\hline $250-500 \mathrm{ribu} / \mathrm{bulan}$ & 84 & 49.4 & 62.9 \\
\hline $500 \mathrm{ribu}-1$ juta/bulan & 45 & 26.5 & 89.4 \\
\hline 1 juta-2 juta/bulan & 7 & 4.1 & 93.5 \\
\hline$>1$ juta/bulan & 11 & 6.5 & 100.0 \\
\hline
\end{tabular}

Jumlah anggota keluarga responden maksimum sebanyak 10 orang, dengan rata-rata anggota keluarga berjumlah 4 orang. Nilai tanah masyarakat minimum sebesar Rp 50 ribu, dan maksimum tanah mereka bernilai Rp 50 juta dengan rata-rata nilai tanah mereka sebesar Rp 407.526. Sementara itu, nilai bangunan masyarakat minimum sebesar Rp 30 ribu dan maksimum bernilai Rp 200 juta dengan rata-rata nilai bangunan sebesar Rp 4.815.484.

Harga lahan pertanian rata-rata sebesar Rp 77.765 per $\mathrm{m}^{2}$ dengan harga lahan minimum sebesar Rp 50.000 dan maksimum sebesar Rp 650.000 per $\mathrm{m}^{2}$. Biaya produksi sekali panen rata-rata sebesar Rp 1.162.655 dengan biaya maksimum sebesar Rp 12 juta.

Erupsi gunung Merapi menghasilkan timbunan material dengan tinggi maksimum $500 \mathrm{~cm}$. Sementara jarak tempat tinggal dengan gunung Merapi rata-rata sejauh 10,13 km. Sedangkan jarak dengan pusat pertokoan, pusat kesehatan, dan pusat pendidikan masing-masing rata-rata sejauh $13,49 \mathrm{~km}, 29,98$, dan 21,93 km. 
Tabel 5. Statistik deskriptif responden

\begin{tabular}{|l|r|r|r|r|}
\hline & Minimum & Maximum & Mean & Std. Deviation \\
\hline Jumlah anggota keluarga & 0 & 10 & 4 & 1,41 \\
\hline Nilai tanah & 50.000 & 50.000 .000 & $407.525,98$ & $3.874 .565,16$ \\
\hline Nilai bangunan & 30.000 & 200.000 .000 & $4.815 .483,87$ & $26.217 .779,72$ \\
\hline Harga lahan pertanian $\left(\right.$ per m $\left.^{2}\right)$ & 50.000 & 650.000 & $77.765,35$ & $61.632,36$ \\
\hline Biaya produksi sekali panen & 50.000 & 12.000 .000 & $1.162 .655,66$ & $2.563 .696,57$ \\
\hline Hasil sekali panen $(\mathrm{kg})$ & 1 & 400 & 60,46 & 94,27 \\
\hline Tinggi timbunan material Merapi $(\mathrm{cm})$ & 0 & 500 & 33,619 & 90,475 \\
\hline Jarak dengan gunung Merapi $(\mathrm{km})$ & 1 & 48 & 10,13 & 5,25 \\
\hline Jarak tempat tinggal ke pusat pendidikan $(\mathrm{km})$ & 0,1 & 500 & 21,929 & 82,73 \\
\hline Jarak tempat tinggal ke supermaket/pertokoan $(\mathrm{km})$ & 0,0 & 700 & 13,498 & 58,11 \\
\hline Jarak tempat tinggal ke pusat kesehatan $(\mathrm{km})$ & 0,1 & 500 & 29,978 & 93,822 \\
\hline
\end{tabular}

Berdasarkan hasil survei di 4 kecamatan yaitu Turi, Pakem, Cangkringan dan Ngemplak, dari 200 responden yang memberikan jawaban ternyata terdapat 6,5\% yang kehilangan mata pencaharian, yang semula mereka adalah petani tetapi setelah erupsi Merapi mereka tidak bekerja lagi. Hal ini dimungkinkan karena rusaknya lahan pertanian yang mereka miliki atau mereka garap. Sementara, $55,5 \%$ dari mereka yang berprofesi sebagai petani, setelah erupsi mereka masih memiliki profesi yang sama. Terdapat $29 \%$ dari total responden di 4 kecamatan tersebut tetap berprofesi dalam bidang yang sama. Sedangkan sisanya ( $9 \%$ ) beralih profesi setelah adanya erupsi Gunung Merapi.

Tabel 6. Pendapatan sebelum dan setelah erupsi

\begin{tabular}{|l|l|r|r|r|r|r|r|}
\hline \multicolumn{2}{|c|}{} & \multicolumn{5}{c|}{ Pendapatan Setelah Erupsi } & \multicolumn{1}{c|}{ Total } \\
\cline { 3 - 8 } \multicolumn{2}{|c|}{} & $\begin{array}{c}<250 \\
\text { ribu/bln }\end{array}$ & $\begin{array}{l}250-500 \\
\text { ribu/bln }\end{array}$ & $\begin{array}{c}500 \text { ribu- } \\
1 \text { juta/bln }\end{array}$ & $\begin{array}{c}1 \text { juta-2 } \\
\text { juta/bln }\end{array}$ & $\begin{array}{c}>1 \\
\text { juta/bln }\end{array}$ & $\begin{array}{c}<250 \\
\text { ribu/bln }\end{array}$ \\
\hline $\begin{array}{l}\text { Pendapatan } \\
\begin{array}{l}\text { Sebelum } \\
\text { Erupsi }\end{array}\end{array}$ & $\begin{array}{l}250-500 \\
\text { ribu/bln }\end{array}$ & 12 & 40 & 0 & 0 & 0 & 52 \\
\cline { 2 - 8 } & $\begin{array}{l}500 \mathrm{ribu}-1 \\
\text { juta/bln }\end{array}$ & 7 & 42 & 30 & 0 & 0 & 79 \\
\cline { 2 - 8 } & $1-2 \mathrm{juta} / \mathrm{bln}$ & 3 & 2 & 11 & 5 & 1 & 22 \\
\cline { 2 - 8 } & $>1$ juta/bln & 1 & 0 & 1 & 2 & 10 & 14 \\
\hline \multicolumn{1}{|c|}{ Total } & 23 & 84 & 42 & 7 & 11 & 167 \\
\hline
\end{tabular}

Di Kecamatan Turi, Pakem, Cangkringan dan Ngemplak, dari 167 responden yang memberikan jawaban ternyata $47,3 \%$ mengalami penurunan pendapatan. Sedangkan penduduk tetap memiliki pendapatan yang sama per bulan sebesar $50,89 \%$ dari total jawaban responden.

Menurut jawaban responden, nilai bangunan dipengaruhi oleh jarak tempat tinggal dengan Gunung Merapi. Semakin dekat 1 km dengan Gunung Merapi, maka harga semakin menurun Rp 9236,00. Semakin besar risiko yang akan dihadapi oleh masyarakat akan menurunkan permintaan akan rumah yang menyebabkan turunnya harga rumah. Risiko meletusnya gunung Merapi menjadi salah satu pertimbangan untuk membeli rumah di sekitar gunung Merapi, dan kecenderungan orang yang bersifat risk averse (menghindar dari risiko) akan menurunkan minat untuk membeli rumah yang jaraknya semakin berdekatan dengan gunung Merapi. 
Meskipun tidak dapat dipungkiri bahwa jarak dengan pusat pertokoan berpengaruh terhadap harga rumah. Sedangkan semakin dekat $1 \mathrm{~km}$ dengan pusat pertokoan, maka harga rumah semakin meningkat $\mathrm{Rp}$ 9594,00. Hal ini menunjukkan bahwa tingginya aktifitas perekonomian di suatu wilayah akan mendorong naiknya harga rumah di wilayah tersebut. Masyarakat yang tinggal di wilayah yang berdekatan dengan pusat kegiatan ekonomi akan diuntungkan dengan tersedianya berbagai fasilitas dan keperluan untuk memenuhi kebutuhan sehari-hari. Oleh karena itu, mereka menilai lebih tinggi terhadap tempat tinggal mereka.

Tabel 7. Faktor-Faktor yang Berpengaruh pada Nilai Rumah/Bangunan

\begin{tabular}{|l|c|c|}
\hline \multicolumn{1}{|c|}{ Variabel } & Koefisien & $t$-stat \\
\hline Ukuran Tanah & 22,457 & $(0,988)$ \\
\hline Struktur rumah & 32258,586 & $(1,402)$ \\
\hline Jarak dengan Gunungi Merapi & $9235,908^{*}$ & $(1,787)$ \\
\hline Jarak dengan sungai & $-16,427$ & $(-0,287)$ \\
\hline Tinggi timbunan material Merapi & $-761,002$ & $(-0,419)$ \\
\hline Jarak tempat tinggal ke pusat kesehatan/RS & 180,271 & $(0,557)$ \\
\hline Jarak tempat tinggal ke pusat pendidikan & $-157,243$ & $(-0,489)$ \\
\hline Jarak tempat tinggal ke Supermaket/Pertokoan & $9593,988^{* * *}$ & $(4,885)$ \\
\hline
\end{tabular}

*signifikan pada level 10\%, *** signifikan pada level 1\%

Sementara itu, nilai lahan pertanian dipengaruhi oleh rupiah yang dihasilkan per satu kali panen. Semakin besar rupiah yang diperoleh setiap kali panen, maka semakin mahal harga lahan tersebut. Meskipun nilai koefisiennya tidak begitu besar, tetapi dapat dicermati bahwa orang yang rasional akan selalu memaksimumkan utilitasnya. Apabila seseorang akan membeli suatu lahan pertanian, maka salah satu tujuannya adalah menghasilkan keuntungan yang sebesar-besarnya sehingga bisa memaksimumkan utilitasnya. Oleh karena itu, hasil per sekali panen menjadi salah satu faktor yang mendorong tingginya nilai lahan pertanian.

Tabel 8. Faktor-Faktor yang Berpengaruh terhadap Harga Lahan Pertanian

\begin{tabular}{|l|r|r|}
\hline \multicolumn{1}{|c|}{ Variabel } & \multicolumn{1}{c|}{ Koefisien } & \multicolumn{1}{c|}{-stat } \\
\hline Biaya produksi yang dikeluarkan satu kali panen & $-0,012$ & $(-0,487)$ \\
\hline Hasil per sekali panen & $0,026^{*}$ & $(2,656)$ \\
\hline Besar kerugian karena erupsi Merapi & 0,000 & $(1,596)$ \\
\hline Tinggi timbunan material Merapi & $-3129,27^{* *}$ & $(1,876)$ \\
\hline
\end{tabular}

*signifikan pada level 10\%, ** signifikan pada level 5\%

Sebaliknya, risiko yang akan dihadapi jika membeli lahan di kawasan yang termasuk rawan bencana menjadi salah satu faktor yang menurunkan nilai lahan pertanian. Erupsi gunung Merapi merupakan salah satu bencana yang tidak terelakkan, yang menghasilkan material vulkanik. Timbunan material vulkanik ini yang menutupi lahan terutama lahan pertanian bervariasi tingginya tergantung lokasi lahan atau ketinggian permukaan tanah. 
Semakin tinggi timbunan material yang dihasilkan dari erupsi Merapi, maka semakin murah harga lahan tersebut. Pemilik/buruh lahan pertanian harus berjuang keras untuk membersihkan timbunan dan menerima kerugian yang cukup besar karena rusaknya tanaman mereka. Meskipun dalam jangka panjang timbunan abu vulkanik dapat menyuburkan tanah, akan tetapi orang cenderung berpikir dalam jangka pendek yang akan mempengaruhi penilaian mereka terhadap lahan pertanian yang terkena dampak erupsi.

Harga implisit marjinal (Marginal implicit prices) variable tinggi timbunan material vulkanik dihitung dengan mendiferensiasikan fungsi hedonic price terhadap variable tinggi timbunan material vulkanik. Oleh karena itu, untuk rumah tangga tertentu, setiap unit kenaikan timbunan material vulkanik menghasilkan suatu estimasi penurunan nilai lahan pertanian sebesar -3129,27 dikalikan dengan nilai lahan pertanian dibagi tinggi timbinan material vulkanik yang terkait. Misalnya, suatu rumah tangga yang nilai lahan pertaniannya sebesar Rp 100.000 dengan ketinggian timbunan $4 \mathrm{~cm}$ akan menderita marginal damage sebesar Rp 78.231.750. Dengan kata lain, rumah tangga tersebut diekspektasikan memiliki willingness to pay tidak lebih dari In other words, this particular household is expected to be willing to pay no more than $\mathrm{Rp} 1,000.00 \mathrm{Rp} 78.231 .750$ untuk menghindari kerusakan pada lahan pertanian mereka untuk setiap unit kenaikan timbunan material vulkanik gunung Merapi.

Dengan mempertimbangkan sampel yang diteliti sebanyak N, maka marginal willingness to pay (MWTP) rata-rata sampel dapat dihitung sebagai marginal damages sebagai berikut:

\section{$N^{-1} \sum\left[(\delta p / \delta H E I G H T)\left(p_{i} / H E I G H T_{i}\right)\right]$}

Jadi, jika sample cukup mewakili Kabupaten Sleman, rata-rata rumah tangga memiliki willingness to pay sekitar $\mathrm{Rp} 653.800,00$ untuk setiap penurunan tinggi timbunan material vulkanik pada lahan pertanian mereka. Nilai tersebut mau dibayarkan agar timbunan material vulkanik lebih rendah sehingga lahan pertanian mereka bisa dimanfaatkan kembali sebagai mata pencaharian mereka untuk memenuhi kebutuhan hidup.

\section{Kesimpulan dan Saran}

Bencana erupsi Gunung Merapi ini telah mengakibatkan kerusakan dan kerugian besar di sejumlah desa dan kecamatan terutama di wilayah Kabupaten Sleman DI Yogyakarta yang meliputi kecamatan Turi, Pakem, Cangkringan, dan Ngemplak. 
Berdasarkan hasil survey, nilai bangunan dipengaruhi oleh jarak tempat tinggal dengan Gunung Merapi. Semakin dekat 1 km dengan Gunung Merapi, maka harga semakin menurun Rp 9236,00. Semakin besar risiko yang akan dihadapi oleh masyarakat akan menurunkan permintaan akan rumah yang menyebabkan turunnya harga rumah. Selain itu, jarak dengan pusat pertokoan berpengaruh terhadap harga rumah. Sedangkan semakin dekat $1 \mathrm{~km}$ dengan pusat pertokoan, maka harga rumah semakin meningkat Rp 9594,00. Hal ini menunjukkan bahwa tingginya aktifitas perekonomian di suatu wilayah akan mendorong naiknya harga rumah di wilayah tersebut.

Nilai lahan pertanian dipengaruhi oleh rupiah yang dihasilkan per satu kali panen dan tingginya timbunan material Merapi. Semakin besar rupiah yang diperoleh setiap kali panen, maka semakin mahal harga lahan tersebut. Risiko yang akan dihadapi jika membeli lahan di kawasan yang termasuk rawan bencana menjadi salah satu faktor yang menurunkan nilai lahan pertanian. Semakin tinggi timbunan material yang dihasilkan dari erupsi Merapi, maka semakin murah harga lahan tersebut.

Rata-rata rumah tangga memiliki willingness to pay sekitar $\mathrm{Rp} 653.800,00$ untuk setiap penurunan tinggi timbunan material vulkanik pada lahan pertanian mereka. Nilai tersebut mau dibayarkan agar timbunan material vulkanik lebih rendah sehingga lahan pertanian mereka bisa dimanfaatkan kembali sebagai mata pencaharian mereka untuk memenuhi kebutuhan hidup.

Dengan melihat adanya pengaruh tingginya timbunan material terhadap turunnya nilai lahan pertanian, maka perlu adanya upaya untuk memulihkan kembali lahan pertanian dengan mengatasi bersama-sama risiko tersebut baik bekerjasama dengan pemerintah daerah maupun sektor swasta agar mata pencaharian penduduk yang sebagian besar petani dapat kembali pulih. Disamping itu, peningkatan produktifitas lahan pertanian sangat diperlukan. Oleh karena itu, bantuan pelatihan ketrampilan untuk meningkatkan produktifitas pertanian, disamping juga bantuan pupuk dan tanaman produktif yang dapat bertahan di lingkungan Merapi sangat diharapkan untuk menjadi stimulus bagi bangkitnya perekonomian masyarakat di sekitar Merapi dalam menopang kehidupannya.

\section{Daftar Pustaka}

BAKORNAS PB. (2005). Panduan Pengenalan Karakteristik Bencana dan Upaya Mitigasinya di Indonesia. BAKORNAS PB. Jakarta.

Bappenas. (2004). Perencanaan Kebijakan Nasional Pengendalian Banjir. Bapenas. Jakarta

Batubara, Cosmas. (1984). Kebijaksanaan Pembangunan Perumahan Nasional: Sebuah Sumbang Saran, Masalah Sejumlah Pemukiman Kota, Penerbit Alumni, Bandung. 
Bintarto. (1977). Pengantar Geografi Desa, Penerbit UP, Spring, Yogyakarta.

Dianto. (2003). Kajian Banjir pada Sungai Dolok dan Sungai Babon di Wilayah Semarang-Demak. Tesis. Fakultas Teknik UGM. Tidak dipublikasikan.

Gunadi. (1991). Penggunaan Lahan, Kursus Evaluasi Sumber Daya Lahan, Fakultas Geografi: Fakultas Geografi UGM, Yogyakarta.

Hofman, David, dan Patricia Brukoff. (1999). Insuring Public Finances Against Natural Disasters, A Survey of Options and Recent Initiatives, IMF Infrastructure Department, Latin America and Caribbean Region, Washington.

Jayadinata, J.T. (1999). Tataguna Tanah dalam Perencanaan Pedesaan, Perkotaan, dan Wilayah, ITB Bandung.

Karmono, M. (1988). Evaluasi Sumber Daya Lahan, Yogyakarta: PUSPICS, Fakultas Geografi UGM, Yogyakarta.

Karmono, M. (1986). Pemanfaatan Penelitian Sumberdaya Lahan, Bahan Kuliah Puspics, Yogyakarta, Fakultas Geografi.

Komplainen, S. (2006). Vulnerability Concepts in Hazards and Risk Assesment. Special Paper. Geological Survey of Finland. Finland. www. Saunalahti.fl.

Kuncoro, Mudrajad. (2002). Analisis Spasial dan Regional: Studi Anglomerasi dan Kluster Industri Indonesia. UPP AMP YKPN. Yogyakarta.

Mangunsukardjo, Karmono. (1985). Invetarisasi Sumberdaya Lahan di Daerah Aliran Sungai Serayu dengan Tinjauan Geomorfologi, Disertasi, Ilmu Geografi UGM,

Marsoedi, DS. (1996). Pedoman Klasifikasi Landform, Bogor: Centre for Soil and Agroclimate.

Pristika, A., and Tsakiris, G. (2007). Flood Risk Assesment: A Methodological Framework. Center Foe The Assesment of Natural Hazards and Proactive Planning. University of Athen. Greece. www.central.ntua.gr

Rashed, T. M. G. E. (2003). Measuring the environmental context of social vulnerability to urban earthquake hazards: An integrative remote sensing and GIS approach. University of California, Santa Barbara, PhD Thesis. Wood, N.J.,dan J.W. Good. (2004)., Vulnerability of Ports and Harbor Communities to Earthquake and Tsunami Hazards: The Use of GIS in Community Planning. Coastal Management, vol 32 (3), pp.

Reed, Shelia, B. (1995). Pengantar tentang Bahaya, Program Pelatihan Manajemen Bencana, UNDP Socio-Economic Effects of Natural Disasters (Santiago, Chile: United Nations)

Sinaga, M. Gunadi, Yusron, H., Suwadi, M. (1992). Inventarisasi Pengunaan Lahan di Kecamatan Baturetno, Wonogiri, Jawa Tengah, Hasil Penelitian, Fakultas Geografi UGM. Yogyakarta.

Sitorus, S.R.P. (1995). Evaluasi Sumber Daya Lahan, Bandung: Tarsito.

Siswoko. (2005). Banjir, Masalah Banjir dan Upaya Mengatasinya. Makalah Pelantikan Pengurus HATHI Cabang Sulsel Periode 2005-2008. Makasar, 19 Maret 2005.

Swiss Re. (1997). Too Little Reinsurance of Natural Disasters in Many, Sigma No. 7/1997.

Tjasyono, H.K. (1999). Klimatologi. Penerbit ITB. Bandung. 
United Nations Development Programme. (1992). Tinjauan Umum Manajemen Bencana, Program Pelatihan Manajemen Bencana. UNDP-UNDRO.

Verstappen. (1983). Applied Geomorphological Surveys for Environmental Development. Elsevier, Sci., Publ, Comp. Amsterdam.

Wood, M. (2007). Wentworth River Flood Hazard Assesment. Environment Waikato Technical Report. Hamilton East. New Zealand. www.ew.govt.nz .

\section{Instansi terkait}

Dinas Pertanian, Perikanan, dan Kehutanan Kabupaten Sleman.

Dinas Pekerjaan Umum Kabupaten Sleman. 